\title{
Mechanical property analysis of kenaf-glass fibre reinforced polymer composites using finite element analysis
}

\author{
M RAMESH* and S NIJANTHAN \\ Department of Mechanical Engineering, Sri Sai Ram Engineering College, Chennai 600 044, Tamil Nadu, India
}

MS received 29 June 2015; accepted 29 September 2015

\begin{abstract}
Nowadays, natural fibres are used as a reinforcing material in polymer composites, owing to severe environmental concerns. Among many different types of natural resources, kenaf plants have been extensively exploited over the past few years. In this experimental study, partially eco-friendly hybrid composites were fabricated by using kenaf and glass fibres with two different fibre orientations of $0^{\circ}$ and $90^{\circ}$. The mechanical properties such as tensile, flexural and impact strengths of these composites have been evaluated. From the experiment, it was observed that the composites with the $0^{\circ}$ fibre orientation can withstand the maximum tensile strength of 49.27 MPa, flexural strength of 164.35 MPa, and impact strength of $6 \mathrm{~J}$. Whereas, the composites with the $90^{\circ}$ fibre orientation hold the maximum tensile strength of $69.86 \mathrm{MPa}$, flexural strength of $162.566 \mathrm{MPa}$ and impact strength of 6.66 J. The finite element analysis was carried out to analyse the elastic behaviour of the composites and to predict the mechanical properties by using NX Nastran 9.0 software. The experimental results were compared with the predicted values and a high correlation between the results was observed. The morphology of the fractured surfaces of the composites was analysed using a scanning electron microscopy analysis. The results indicated that the properties were in the increasing trend and comparable with pure synthetic fibre reinforced composites, which shows the potential for hybridization of kenaf fibre with glass fibre.
\end{abstract}

Keywords. Natural fibres; kenaf fibre; eco-friendly composites; hybrid; mechanical properties; kenaf-glass fibre composites.

\section{Introduction}

In a view to reduce the cost of production and the harmful destruction, there are a lot of ongoing research works for the possibility of mixing natural fibres with the synthetic fibres by using polymer resins. One of the reasons for this growing interest is that, the natural fibres have a higher specific strength than the glass fibre and a similar specific modulus [1]. Natural fibres are the composite materials designed by nature. Most of the natural fibres, except cotton, are composed of cellulose, hemicellulose, lignin, waxes and several water-soluble compounds [2]. An important attribute of plant fibres is their ability to absorb moisture from the atmosphere comparatively in large quantities because these fibres are hygroscopic in nature. The natural fibres are extracted from the outer stem of the respective plants, possess very good mechanical properties and are used as reinforcing materials in polymer composites [3-5]. However, the products made from natural fibre composite are still limited to the structural applications, owing to their poor mechanical properties [6]. To solve this issue, the natural fibres are hybridized with synthetic fibres to make the composite hybrid. This plays a vital role in many engineering applications and serves as alternative materials to the pure synthetic fibre composites [7-9].

\footnotetext{
*Author for correspondence (mramesh97@gmail.com)
}

Kenaf grows in tropical climates, by requiring minimal fertilizers, water and pesticides [10,11]. Kenaf has already proven eco-friendly and economically feasible feedstock for several bio-energy applications due to its high cellulose and low lignin content [12]. In general, the use of kenaf fibre reinforced composite helps to generate jobs in both rural and urban areas; in addition, it helps to reduce waste, and thus, contributes to a healthier environment [13]. Kenaf fibre is a good reinforcement candidate for high-performance biodegradable polymer composites [14]. It has great potential to use as automotive and construction materials due to its long fibres derived from outer fibrous bark, the bast [15]. The typical images of kenaf plants and fibres are presented in figure 1. Kenaf fibre reinforced composites possess superior mechanical properties based on the strong interaction between the fibre and the resin. Accordingly, the kenaf fibre reinforced composite is a good alternative to conventional polymer composites [16]. Kenaf fibres have exhibited superior properties of polymeric composites under flexural loading conditions when compared with the other natural fibres. Moreover, there is a possibility of replacing the synthetic fibres for flexural loading applications [17].

The identification of the most appropriate natural fibre to be hybridized with glass fibre reinforced polymer composites for the fabrication of automotive component is based on functional performance, weight and product cost [18]. Hybridization of kenaf fibres with glass fibres could be used in automotive components such as bumper beam by 

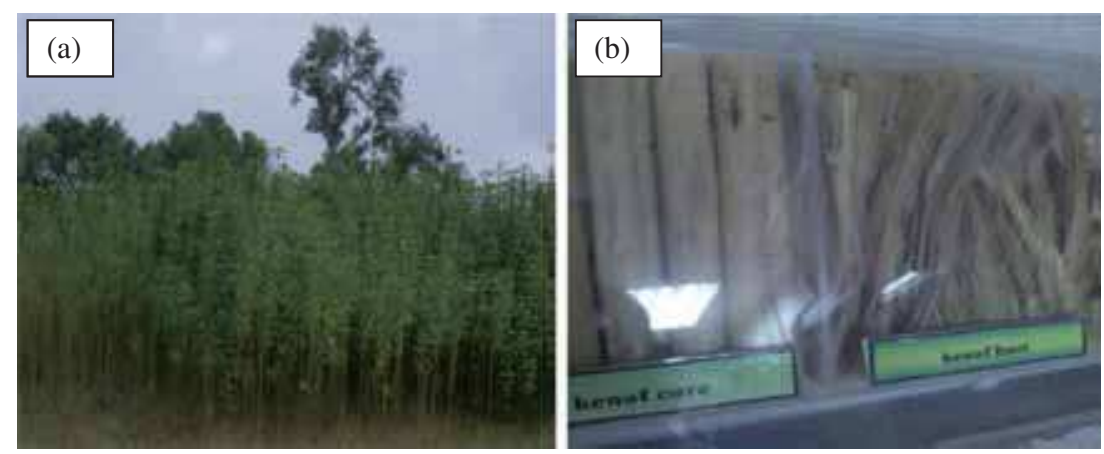

Figure 1. Typical images of (a) kenaf plantation and (b) kenaf fibre.

improving the impact property. Moreover, the impact property is improved by optimizing the structural design parameters or through material improvement [19]. The chemical treatment of the fibre has enhanced the adhesion between the fibre and the matrix and consequently it has improved the mechanical properties of the composites [20]. The NaOHtreated kenaf fibre composites have shown improvement in flexural properties, compared with the untreated fibre composites [21]. Treated and untreated kenaf fibres have been treated in different solutions and have examined through scanning electron microscopy (SEM). The results have indicated that the tensile strength and the modulus of the kenaf fibre composites have been decreased owing to the deteriorating effect of the aging solutions [22]. Mechanical testing of kenaf and basalt fibres reinforced polyethylene composites is carried out and it is found that, the hybridization has successfully increased the performance especially under tensile loading [23]. The effect of fibre content, fibre size and surface treatment on the mechanical and water absorption properties of the kenaf fibre reinforced polyester composites are studied by Farahani et al [24]. The results show that, the length of fibre plays a major role on the mechanical properties and alkali treatment causes a better adhesion between the fibre and matrix. The effect of fibre volume fraction on the properties of kenaf fibre reinforced epoxy composites is evaluated and found that, the tensile strength and modulus of elasticity have increased when there is an increase in the fibre volume [25].

The dynamic mechanical properties of kenaf/PALF fibres reinforced polyethylene composites have been evaluated by Aji et al [26]. From the investigation, they have found that, the storage modulus of all hybrid composites at different fibre ratios have been enormously improved with an increase in the fibre length, marginal difference in loss modulus and no difference in damping factor in regard to variation in fibre length. The impact strength and elongation at break of ethylene acrylate-modified kenaf fibre reinforced polylactic acid composites have been improved by increasing the modifier content but an opposite trend is observed for the tensile strength and modulus [27]. The mechanical properties of kenaf/glass fibre reinforced polypropylene short random oriented hybrid composites material have been predicted by using rule of mixture (RoM) and rule of hybrid mixtures
(RoHM) [28]. Three different compositions are analysed with total fibre contents 30,40 and $50 \mathrm{vol} \%$ and the relative glass fibre contents are varied from 0 to $100 \mathrm{vol} \%$. The outcome of the analysis has showed that, the stiffness of the hybrid is short and randomly oriented composites increases as the overall fibre volume contents increase.

Kenaf and glass fibre reinforced polyester composites have been fabricated through sheet moulding process and they have shown higher tensile, flexural and impact strength [29]. According to Ghani et al [30], the dimensional stability and mechanical properties of kenaf and glass fibre reinforced composites are caused by humidity aging. Moreover, the mechanical properties of the kenaf fibre which get depreciated by the moisture penetration into the kenaf/glass fibre polyester composite even under dissimilar environmental situations. The effects of layering sequence on mechanical properties of kenaf/aramid hybrid composites fabricated through hand lay-up techniques have been evaluated [31]. The results show that, the properties of hybrid composites have improved along with the fabricated composites with aramid as a skin layer when compared with kenaf as skin layers. Placing the glass fibres on the top and bottom layers of the composite specimen possess very good mechanical strength [32]. The effects of fibre orientation on the mechanical properties of banana/kenaf fibre reinforced hybrid polyester composites have been carried out and found that the maximum increase in mechanical strength is observed in the plain hybrid composites rather than in randomly oriented composites [33]. This indicates that, the minimum stress development at the interface of composites is due to the distribution of load transfer along the fibre direction.

The evaluation of the mechanical properties of natural and synthetic fibres reinforced hybrid composites is to find their potential applications; it is an important area of research, which is of current interest. From the available literature, it has been found that, the comprehensive analysis on the mechanical properties of these composites is still a valid problem, and hence, there is a need for carrying out such studies on composite materials. To take the advantage of kenaf fibres, they have been added it with the glass fibres, conjointly to the matrix, so that an optimal, superior but economical composite is obtained. Hence, in this experimental 

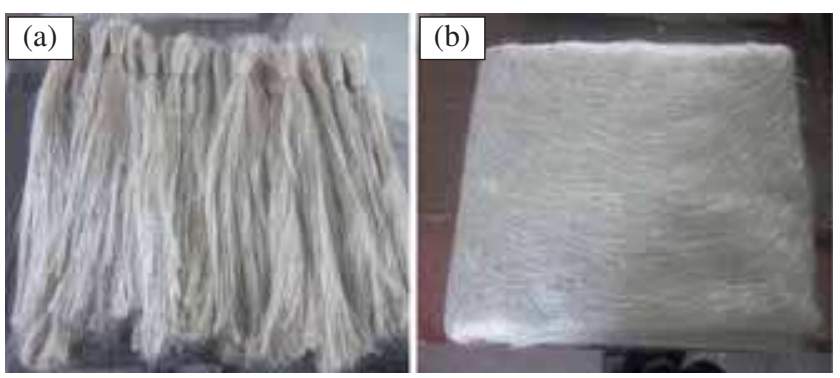

Figure 2. Fibres used for composite fabrication: (a) kenaf fibres and (b) glass fibre.

Table 1. Physical properties of kenaf and glass fibre [12].

\begin{tabular}{lcc}
\hline Property & Kenaf & Glass \\
\hline Cellulose (\%) & $51-52$ & - \\
Lignin (\%) & 17 & - \\
Moisture (\%) & $1.2-14$ & - \\
Density $\left(\mathrm{g} \mathrm{cm}^{-3}\right)$ & $1.2-1.4$ & $2.5-2.6$ \\
Elongation at break $(\%)$ & $9.1-12.3$ & $3-5$ \\
Young's modulus $(\mathrm{GPa})$ & 20 & $65-75$ \\
\hline
\end{tabular}

study, kenaf glass fibres reinforced hybrid composites are prepared with two different fibre orientations of $0^{\circ}$ and $90^{\circ}$. The properties of these hybrid composites such as tensile strength, flexural strength and impact strength have been evaluated. The finite element analysis has been carried out to analyse the elastic behaviour of the composites and also to predict the important mechanical properties by using NX Nastran 9.0 software. The experimental results are compared with the predicted values and have found that high correlation occurs between the results.

\section{Materials and methods}

\subsection{Materials}

In this present experimental study, the composites subjected to the mechanical testing are fabricated from kenaf and glass fibres by using epoxy resin. The kenaf fibre is supplied by Chandra Prakash \& Co., Jaipur, Rajasthan, India. The glass fibre (chopped strand mat), epoxy resin and the hardener HY951, are purchased from M/s. Sakthi Fiber Glass Ltd., in Chennai, India. The kenaf and glass fibres used for the experiment are presented in figure 2 . The properties of fibres used for composite fabrication are presented in table 1 .

\subsection{Composite preparation}

There are many specialized processes available for processing of composite materials, but only the most commonly used commercial process is hand lay-up process. Before lay-up the fibres, the mould is prepared with a tefflon-coated base sheet to ensure that the sample does not stick to the mould. The reinforcing fibres are cut into the required length and they are laid in the mould. The resin is mixed with hardener for quick setting and then it is applied on the fibre surface. A roller is used to impregnate the fibres with the resin and to distribute the resin throughout the fibre surface. The fabrication procedure of composite sample in this experimental study is explained in three simple steps. Step 1: The rust in the mould is cleaned by scrubbing with an abrasive paper. Then, the surface is allowed to dry, after cleaning it with a thinner solution. After drying, the surface is coated with tefflon gel. Step 2: Place the glass fibre over the base plate in the mould and apply resin. Roller is used for proper bonding of resin with fibre. Place the kenaf fibre over glass fibre and apply resin. Step 3: Repeat the process up to 5 layers. The processing steps of the composites are presented in figure 3. In that, three layers (first, third and fifth) are filled with glass fibres and the second and fourth layers are filled with kenaf fibres. In this experiment, the kenaf and glass fibre reinforced hybrid composites are prepared at the room temperature and an average relative humidity of $65 \%$.

\section{Mechanical properties}

The objective of the mechanical testing of composite is the determination of mechanical parameters such as strength and stiffness that will be used for design of composite structures. ASTM standards are used as an instrumental in the evaluation and determination of the properties of materials. These standards are also helpful in guiding the manufacturers and users of such materials in their proper fabrication and testing for the assurance of their quality. The specimen used for mechanical testing is presented in figure 4 .

\subsection{Tensile properties}

A tensile test, also known as tension test, is probably the most fundamental type of mechanical test performed on material. The tensile strength of the composite depends on, how well the load transfers from the broken to the surviving fibres through shear in the resin at the interface and the amount of load a sample can withstand before failure occurred [31]. As the material is loaded, its strength along with how much it elongates was found. These methods are discussed according to ASTM D638 [34] standards for plastics and polymeric materials. The material is loaded in the universal testing machine (Make FIE; Model: UTN 40, S. No. 11/98-2450). Then, the load is applied by increasing rate until it reaches the maximum tensile load. When the load reaches the maximum tensile load it breaks. The load at this point is used to calculate the maximum tensile strength of the composite material. The tensile test set-up with fractured specimen is presented in figure 5 . 

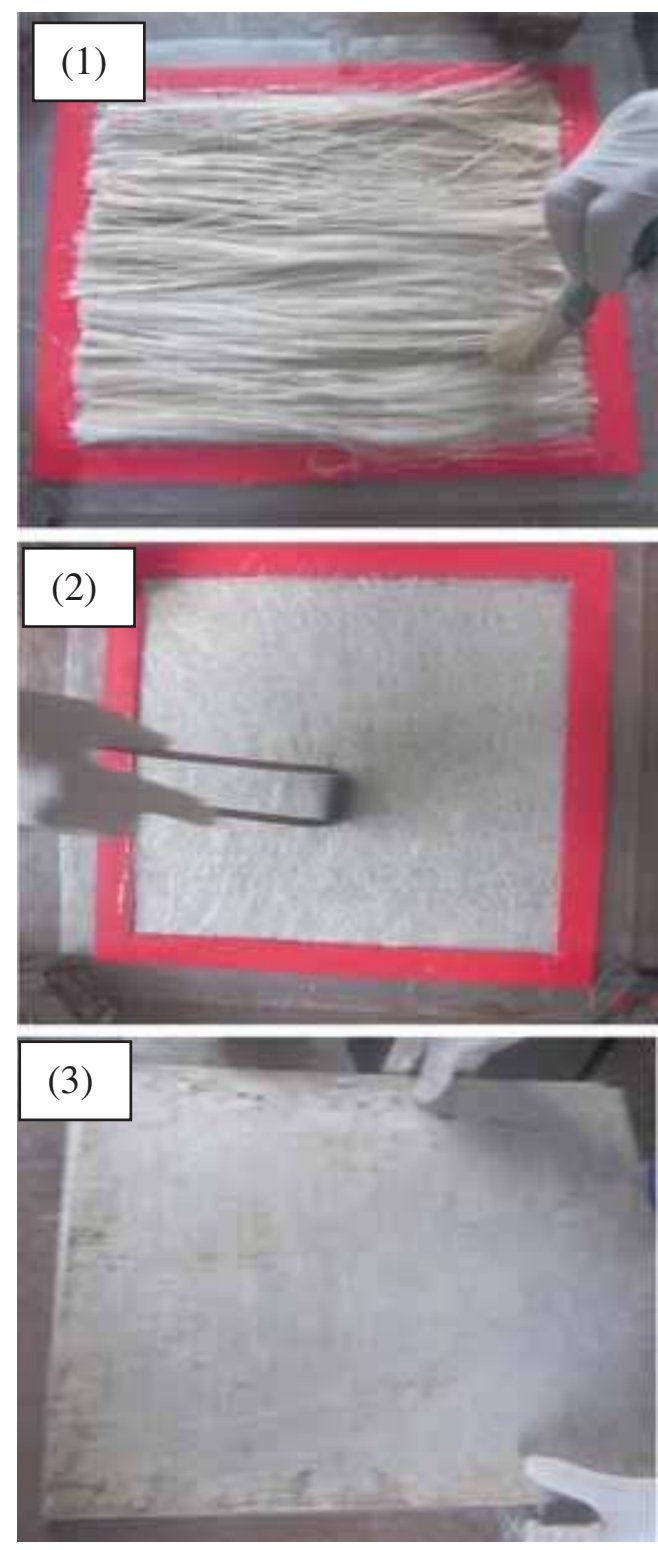

Figure 3. Processing steps of the composite samples.

\subsection{Flexural properties}

Flexural strength, also known as modulus of rupture, bending strength or fracture strength, a mechanical parameter is defined as material's ability to resist deformation under bending load. Flexural strength determines the capability of composites to withstand the bending load before reaching the breaking point [31]. The transverse bending test is the most frequently employed, in which a specimen having rectangular cross-section is bent until fracture uses a three-point flexural test technique. The flexural strength represents the highest stress experienced within the material at its moment of rupture. The flexural strength is the same as the direct tensile strength, if the material is homogeneous. In fact, most of the materials have small or large defects in them, which act to concentrate the stresses locally, effectively by causing a localized weakness. In this present experimental study, the
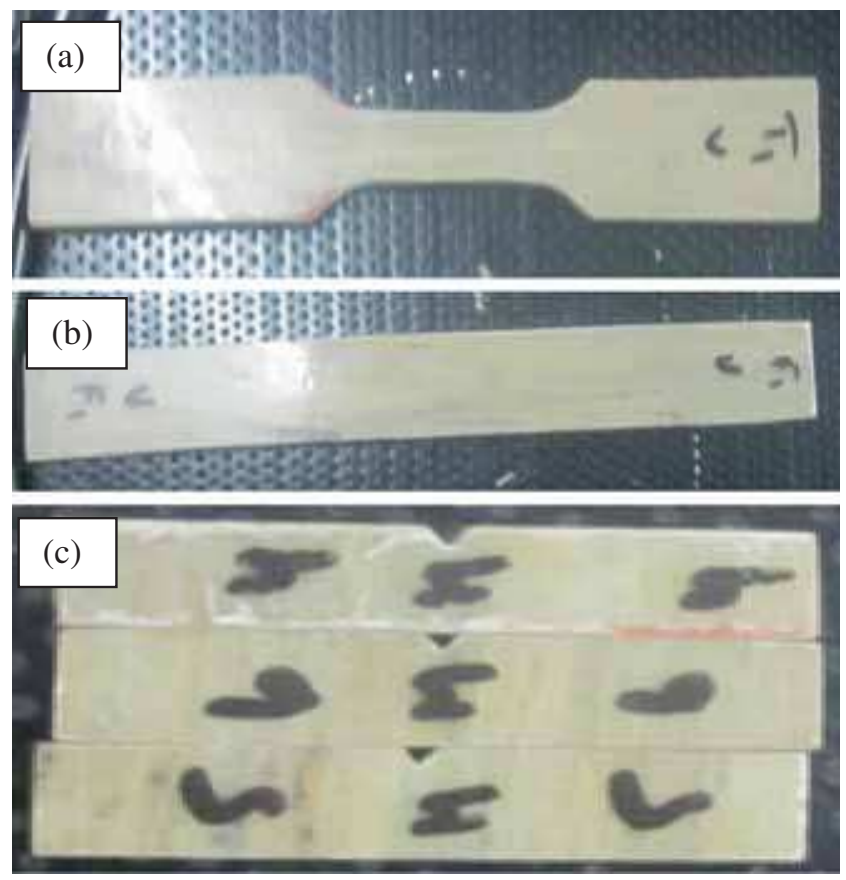

Figure 4. Mechanical test specimen for (a) tensile testing, (b) flexural testing and (c) impact testing.

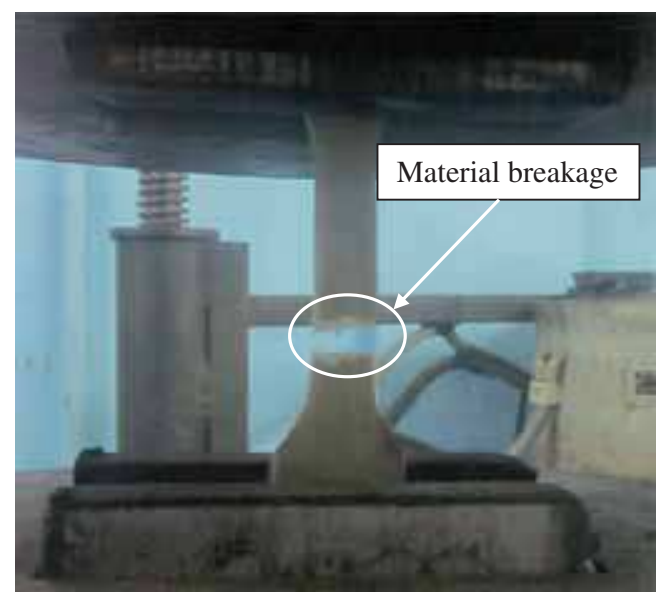

Figure 5. Tensile test set-up with fractured specimen.

flexural test has been conducted as per ASTM D790 [35] by using the same universal testing machine. The flexural test set-up with fractured specimen is shown in figure 6 .

\subsection{Impact properties}

A test is designed to give information on how a material will respond to a suddenly applied load. The charpy impact test, also known as the charpy v-notch test, is a standardized high strain-rate test which determines the amount of energy, which is absorbed by a material during fracture, has been carried out in this experimental study. The samples are prepared for the charpy impact test according to ASTM D6110 [36] standards. The impact strength tests are carried out, 


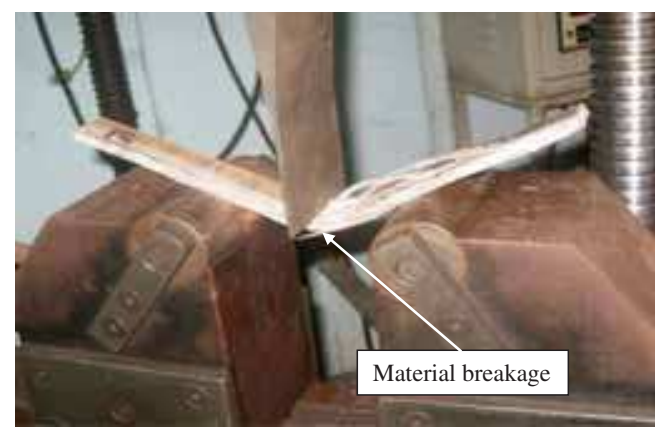

Figure 6. Flexural test set-up with specimen.

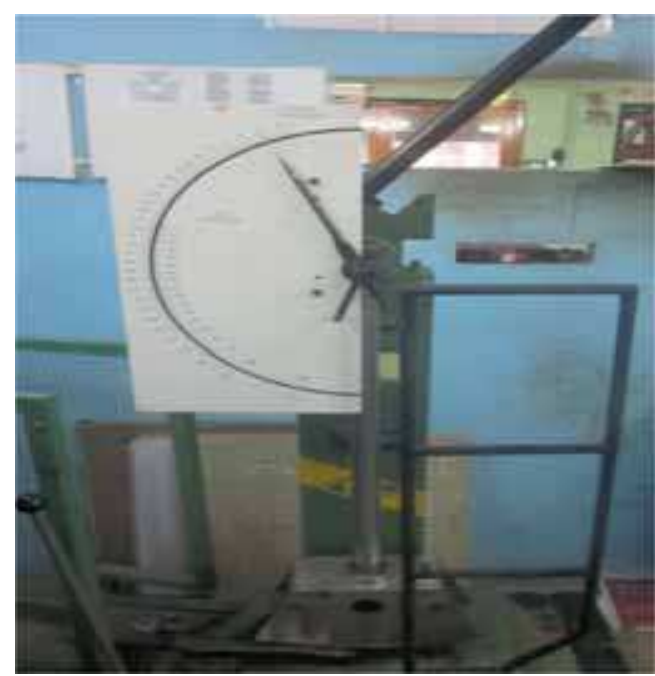

Figure 7. Impact test set-up.

using a charpy impact-testing machine (Model: KL-300, S. No. 96/1054, and Make: Krystal Elmec). During the testing process, the specimen is loaded in the testing machine, and the pendulum is allowed by striking the samples with a heavy impact load. This absorbed energy is a measure of a given material's toughness and acts as a tool to study brittle-ductile nature of a material. The machine used for impact testing is shown in figure 7.

\subsection{Finite element analysis (FEA)}

To study the elastic behaviour of the composites and predict some of the resulting important mechanical properties, a FEA has been carried out. Although, most of these properties are obtained through experimentation. The elasticplastic transition behaviour in composites is not easy to study under experimental conditions, hence a need for theoretical modelling. In addition to validate the experimental findings, the theoretical prediction of these properties has shortened the cycle time, which maximizes the resulting composite properties. The NX Nastran 9.0 is the premier finite element structural analysis solver for linear and nonlinear analysis, dynamic response, rotor dynamics, elasticity and optimization. The Von Mises stress is included in the output
Table 2. Experimental results of the kenaf-glass fibre composite samples.

\begin{tabular}{lccc}
\hline $\begin{array}{l}\text { Fibre } \\
\text { orientation (deg) }\end{array}$ & $\begin{array}{c}\text { Tensile strength } \\
(\mathrm{MPa})\end{array}$ & $\begin{array}{c}\text { Flexural } \\
\text { strength (MPa) }\end{array}$ & $\begin{array}{c}\text { Impact } \\
\text { strength (J) }\end{array}$ \\
\hline 0 & 49.27 & 164.350 & 6 \\
90 & 69.86 & 162.566 & 6.66 \\
\hline
\end{tabular}

Table 3. Mechanical properties are predicted from NX Nastran 9.0.

\begin{tabular}{lccc}
\hline $\begin{array}{l}\text { Fibre } \\
\text { orientation (deg) }\end{array}$ & $\begin{array}{c}\text { Max. tensile } \\
\text { strength (MPa) }\end{array}$ & $\begin{array}{c}\text { Max. flexural } \\
\text { strength (MPa) }\end{array}$ & $\begin{array}{c}\text { Max. impact } \\
\text { strength (J) }\end{array}$ \\
\hline 0 & 40.24 & 153.3 & 6.075 \\
90 & 53.65 & 150.3 & 4.800 \\
\hline
\end{tabular}

for those elements, that supports stress calculation when computing the response of a structure due to random loads. Preliminary results from tensile, flexural and impact tests have indicated that, the composite material is very brittle but has exhibited the linear deformation in its elastic state.

\section{Results and discussion}

In this experimental study, kenaf and glass fibres reinforced hybrid composites are fabricated and their mechanical properties such as tensile, flexural and impact strengths have been evaluated. Table 2 shows that the experimental results have related to the mechanical properties of the kenaf and glass fibres reinforced epoxy composites with different fibre orientation. The predicted values of the mechanical properties from NX Nastran 9.0 are presented in table 3.

\subsection{Tensile strength analysis}

4.1a Experimental analysis: The typical load vs. displacement curve generated directly from the universal testing machine during tensile loading is presented in figure 8. From the figure, it is observed that, there is the gradual increase in the displacement, when the applied load is increased and there is a sudden drop in the displacement after the material breaks. The experimental tensile strength comparison of the composites with two different fibre orientations is presented in figure 9. From the figure, it has been found that, the kenaf-glass fibre reinforced composites with $90^{\circ}$ fibre orientation have more tensile strength than the $0^{\circ}$ fibre orientation composite samples.

4.1b Analysis of tensile strength using FEA: Figure 10 shows the FEA simulation plot for the tensile test specimen with $0^{\circ}$ fibre orientation. The simulated stress distribution for mechanical properties of kenaf-glass fibre reinforced hybrid composites is obtained under different loading 


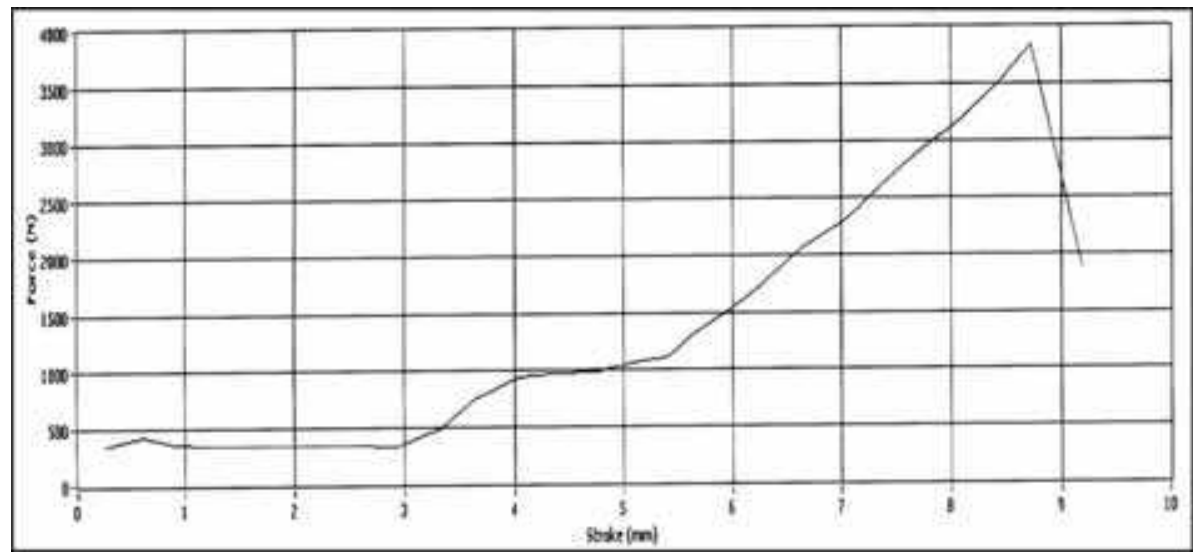

Figure 8. Typical load vs. displacement curve generated directly from the machine during tensile loading.

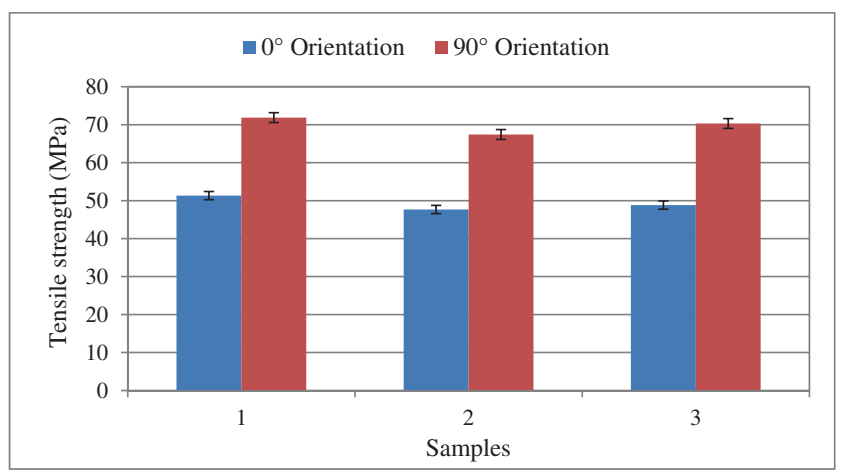

Figure 9. Experimental tensile strength comparison.

conditions. The maximum tensile stress acting on the specimen is $40.24 \mathrm{MPa}$ which is located at the middle portion of the specimen, where the maximum stress occurs. The results from tensile test indicate that the composites are very brittle but have exhibited linear deformation in its elastic state. The FEA simulation result plot for the kenaf-glass fibre reinforced hybrid composite sample with $90^{\circ}$ fibre orientation subjected to the tensile loading is presented in figure 11. From the figure it is found that, the maximum tensile stress acting on the $90^{\circ}$ fibre orientation composite specimen is $53.65 \mathrm{MPa}$, which is located at the middle portion of the specimen, where the maximum stress occurs. The result from tensile test further indicates that the composites are very brittle but have exhibited linear deformation in its elastic state. From the FEA analysis results it is found that the values are closer to the experimental results.

\subsection{Flexural strength analysis}

4.2a Experimental analysis: The typical load vs. displacement curve generated directly from the universal testing machine during flexural loading is presented in figure 12 .
From the figure, it is observed that there is the gradual increase in the displacement, when the applied load is increases and there is a sudden drop in the displacement after the material breaks. The experimental flexural strength comparison of the different fibre orientation composites is presented in figure 13. The figure reveals that, the flexural strength of the $0^{\circ}$ fibre orientation composite samples performs slightly better than the $90^{\circ}$ fibre orientation composite samples. This is due to the direction of load acting on the specimen. From the figure, further it is observed that, the fibre orientation does not have much influence on the flexural properties.

4.2b Analysis of flexural strength using FEA: Figure 14 shows the FEA simulation plot for the flexural test specimen with $0^{\circ}$ fibre orientation. The flexural strength of these composites is found due to the fibre orientation and binding properties. The maximum flexural stress acting on the $0^{\circ}$ fibre orientation specimen is $153.3 \mathrm{MPa}$, which is located at the middle portion of the specimen, where the maximum stress occurs. The FEA simulation result plot for the kenafglass hybrid composite specimen with $90^{\circ}$ fibre orientation is presented in figure 15. From the figure, it is found that, the maximum flexural stress acting on the $90^{\circ}$ fibre orientation composite specimen is $150.3 \mathrm{MPa}$, which is located at the middle portion of the specimen, where the maximum stress occurs. The result from the flexural test, further has indicated that the composites are very brittle but they have exhibited linear deformation in its elastic state. It is also found that the FEA analysis results are closer to the experimental results.

\subsection{Impact strength analysis}

4.3a Experimental analysis: The results obtained from the impact test for kenaf-glass fibre composites are tabulated in table 2. The experimental impact strength comparison of these composite materials is presented in figure 16. From 


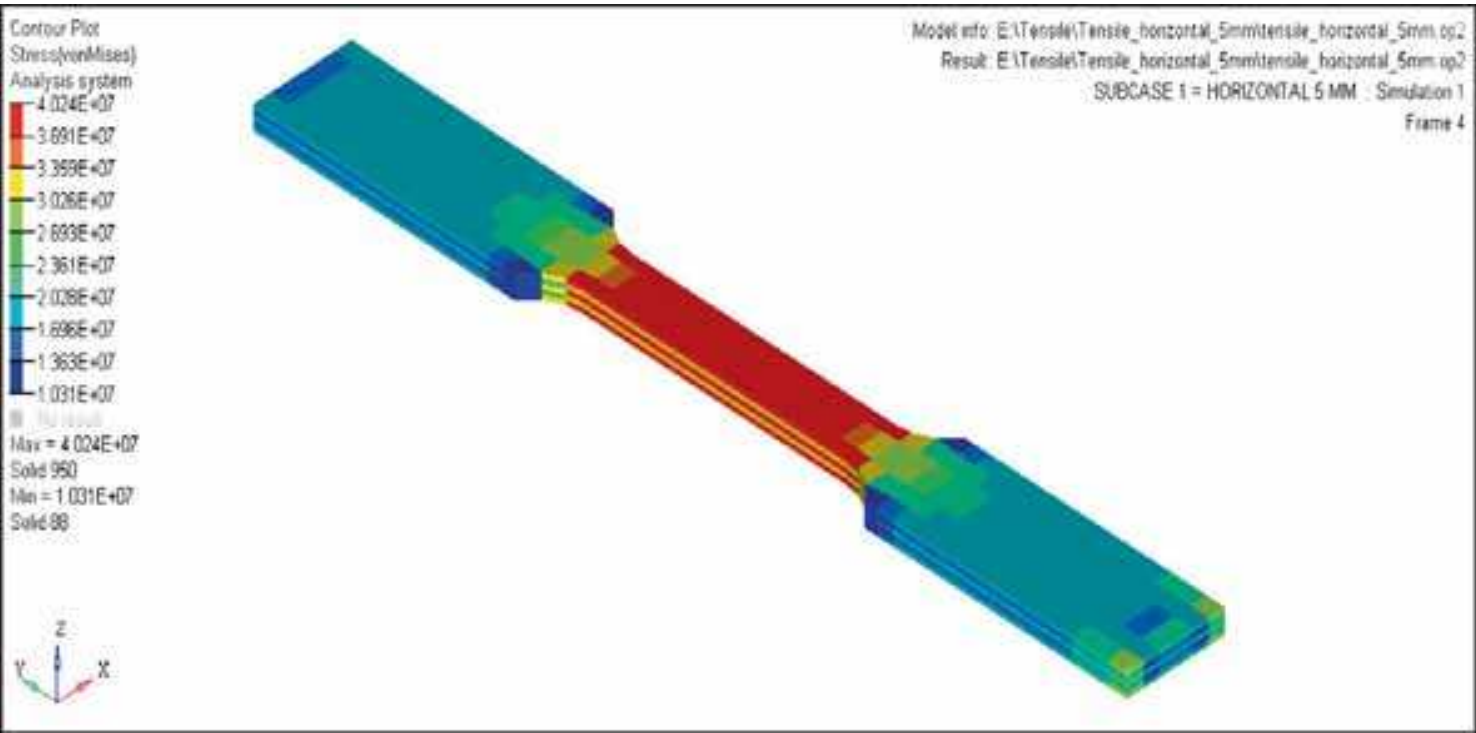

Figure 10. Simulation plot of tensile test specimen with $0^{\circ}$ fibre orientation.

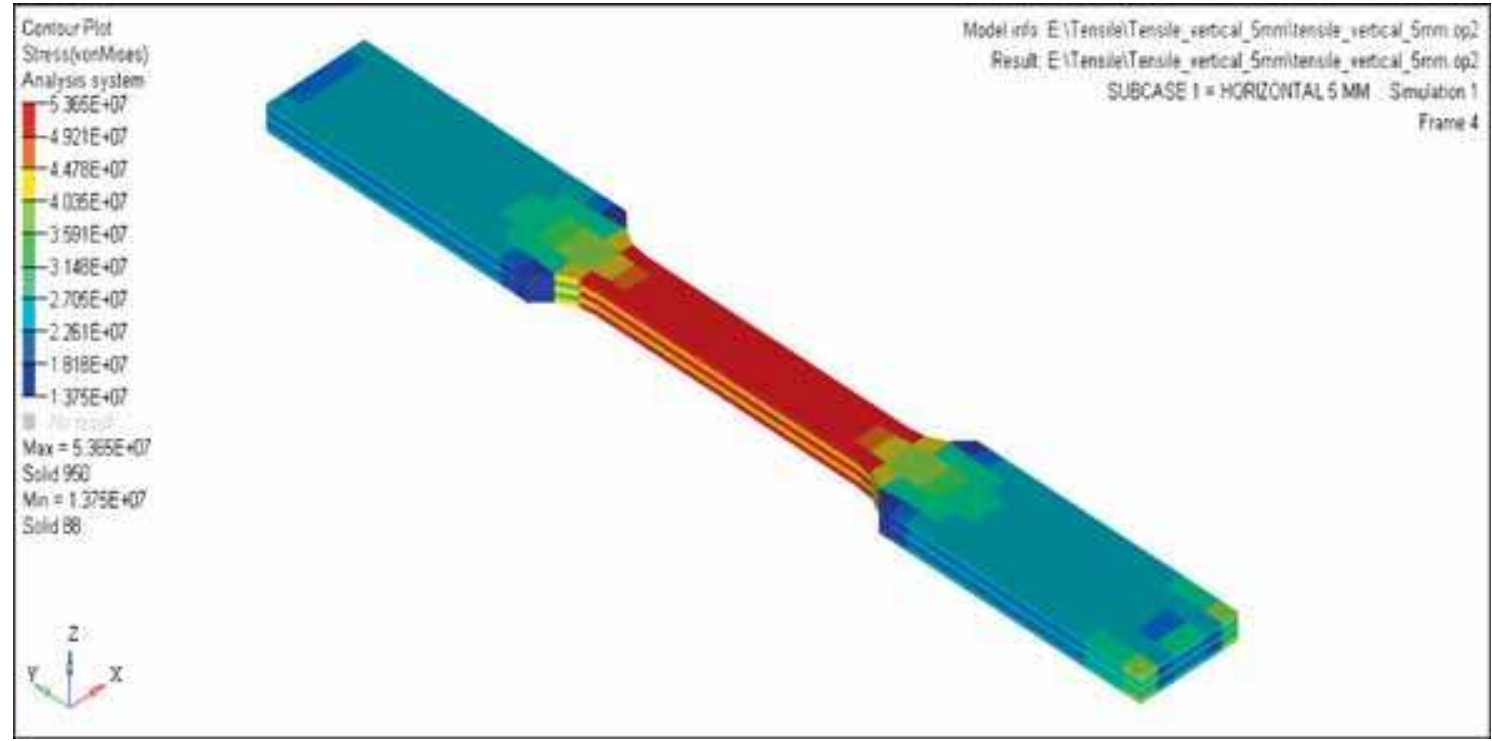

Figure 11. Simulation plot of tensile test specimen with $90^{\circ}$ fibre orientation.

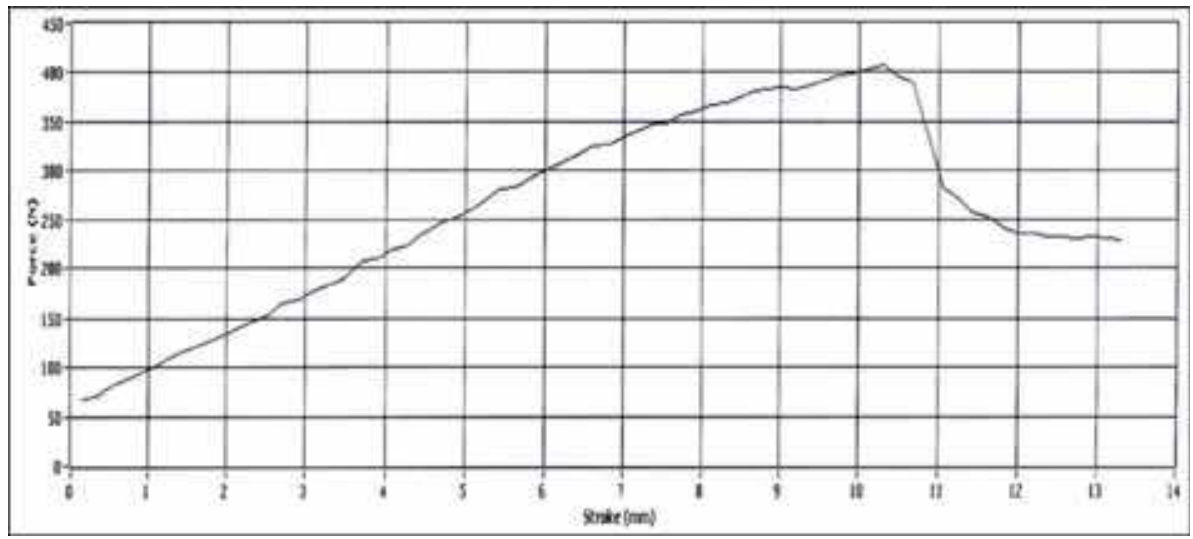

Figure 12. Typical load $v s$. displacement curve generated directly from the machine during flexural loading. 


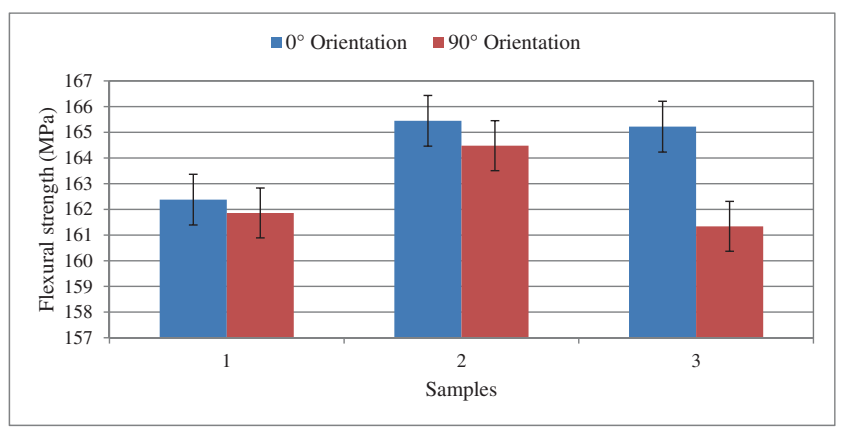

Figure 13. Experimental flexural strength comparison. the figure, it has been found that, kenaf-glass fibre composites with $90^{\circ}$ fibre orientation have more capable of withstanding high impact load than $0^{\circ}$ fibre orientation composite samples.

4.3b Analysis of impact strength using FEA: Figure 17 shows the FEA simulation plot for the impact test specimen with $0^{\circ}$ fibre orientation. The simulated stain energy distribution for mechanical properties of kenaf-glass hybrid composites is obtained under different loading conditions. The maximum strain energy observed for the $0^{\circ}$ fibre orientation specimen is $6.075 \mathrm{~J}$, which is located at the middle

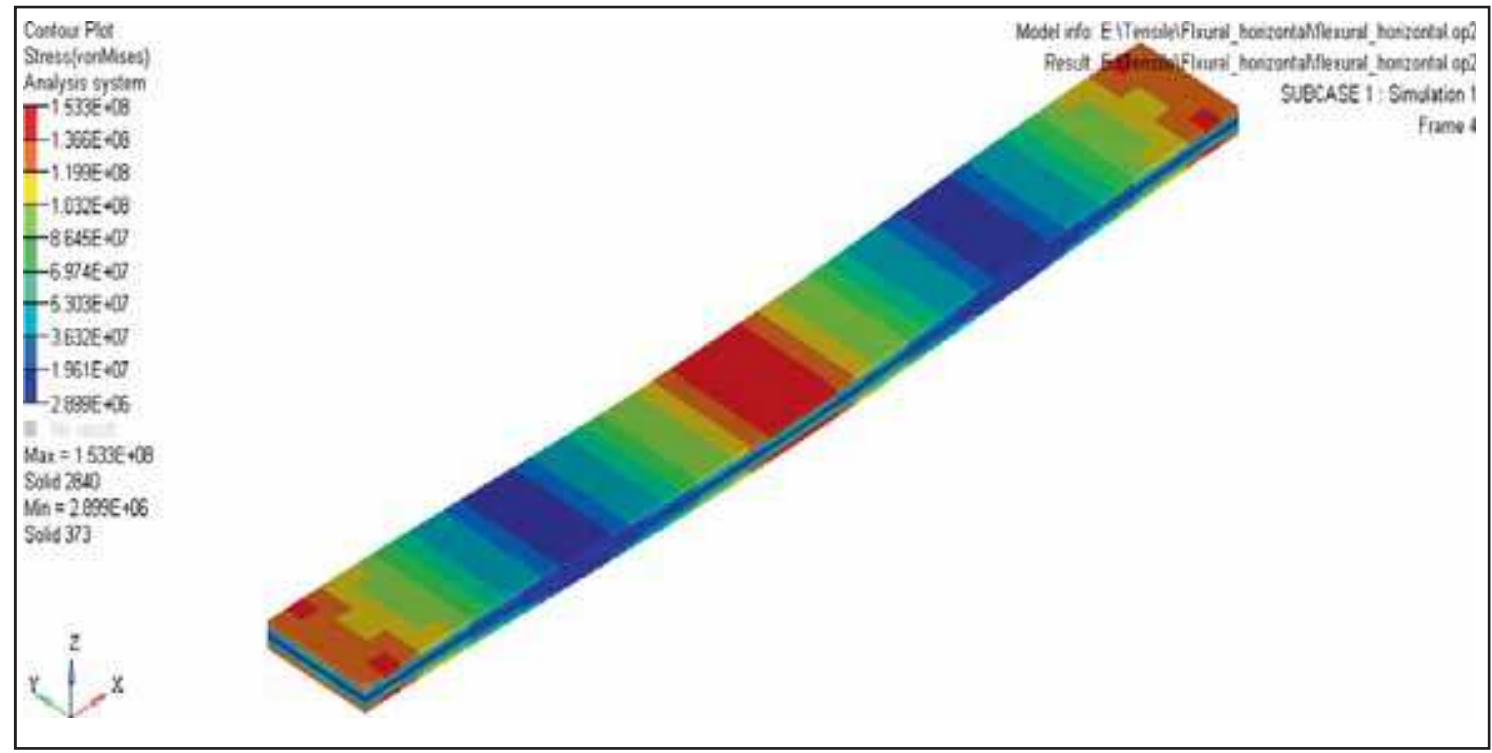

Figure 14. Simulation plot of flexural test specimen with $0^{\circ}$ fibre orientation.

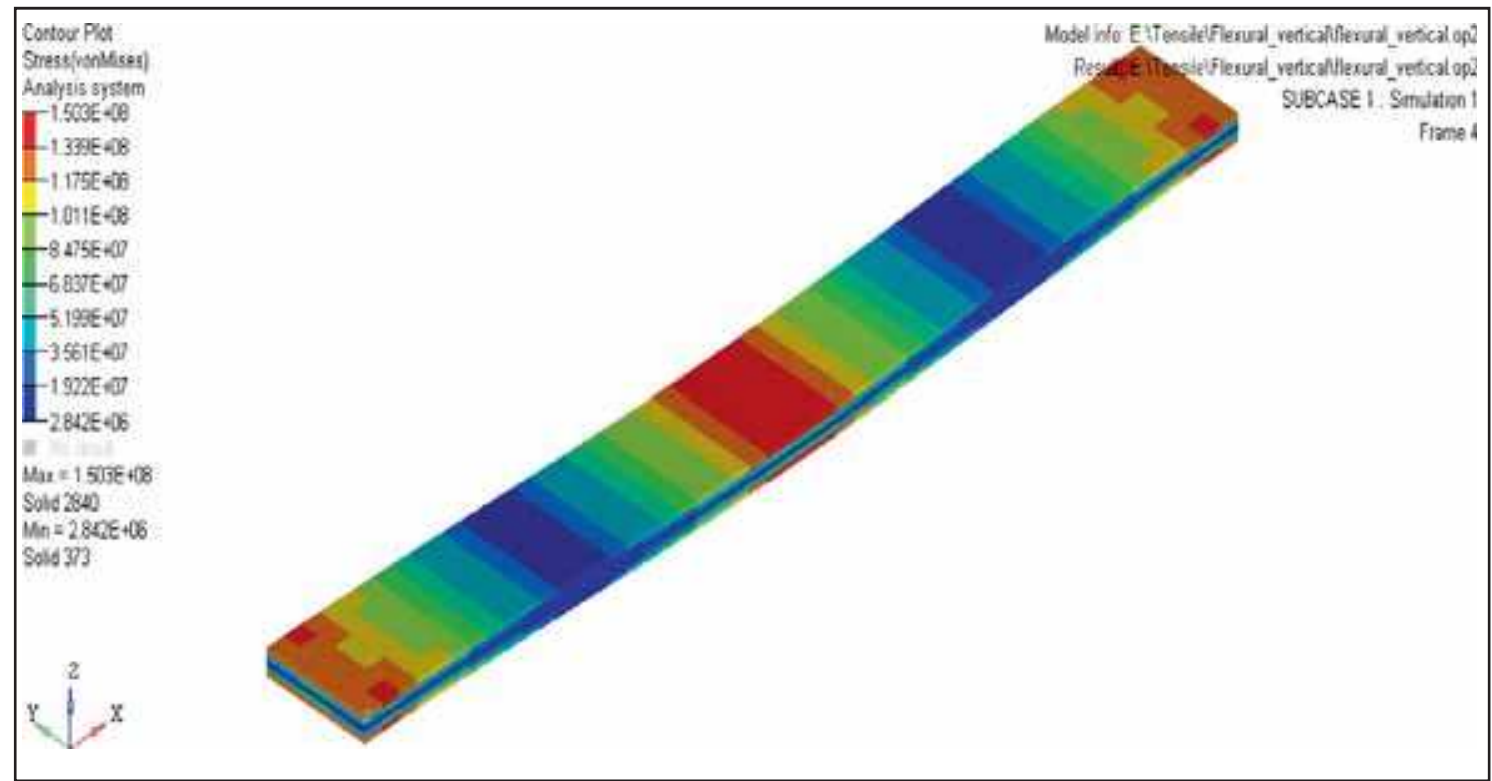

Figure 15. Simulation plot of flexural test specimen with $90^{\circ}$ fibre orientation. 
portion of the specimen, where the maximum stress occurs. The FEA simulation result plot for the kenaf-glass hybrid

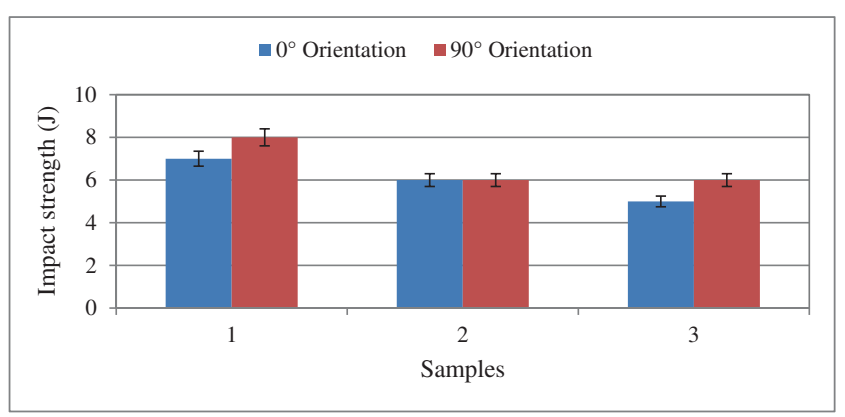

Figure 16. Experimental impact strength comparison. composite specimen with $90^{\circ}$ fibre orientation subjected to flexural loading is presented in figure 18. The maximum strain energy observed by the specimen is $4.8 \mathrm{~J}$, which is located at the middle portion of the specimen, where the maximum stress occurs. Result from impact test further has indicated that the composites are very brittle but have exhibited linear deformation in its elastic state. It is found that the FEA analysis results are closer to the experimental result.

\subsection{Scanning electron microscopy (SEM) analysis}

Figure 19 shows the SEM images of the fractured surfaces of the kenaf-glass fibre composites, which are subjected to tensile loading. The images clearly show the orientation of

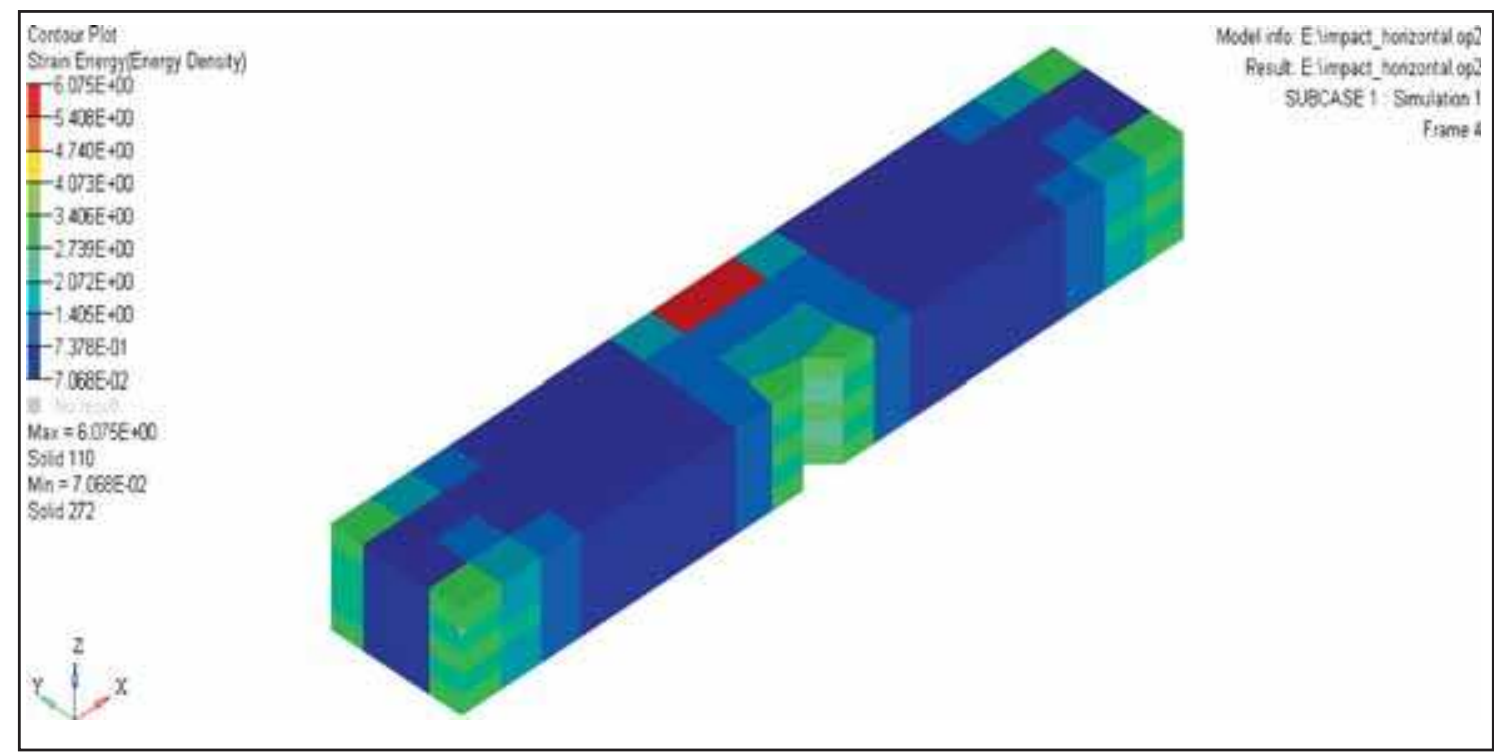

Figure 17. Strain energy distribution of impact test specimen with $0^{\circ}$ fibre orientation.

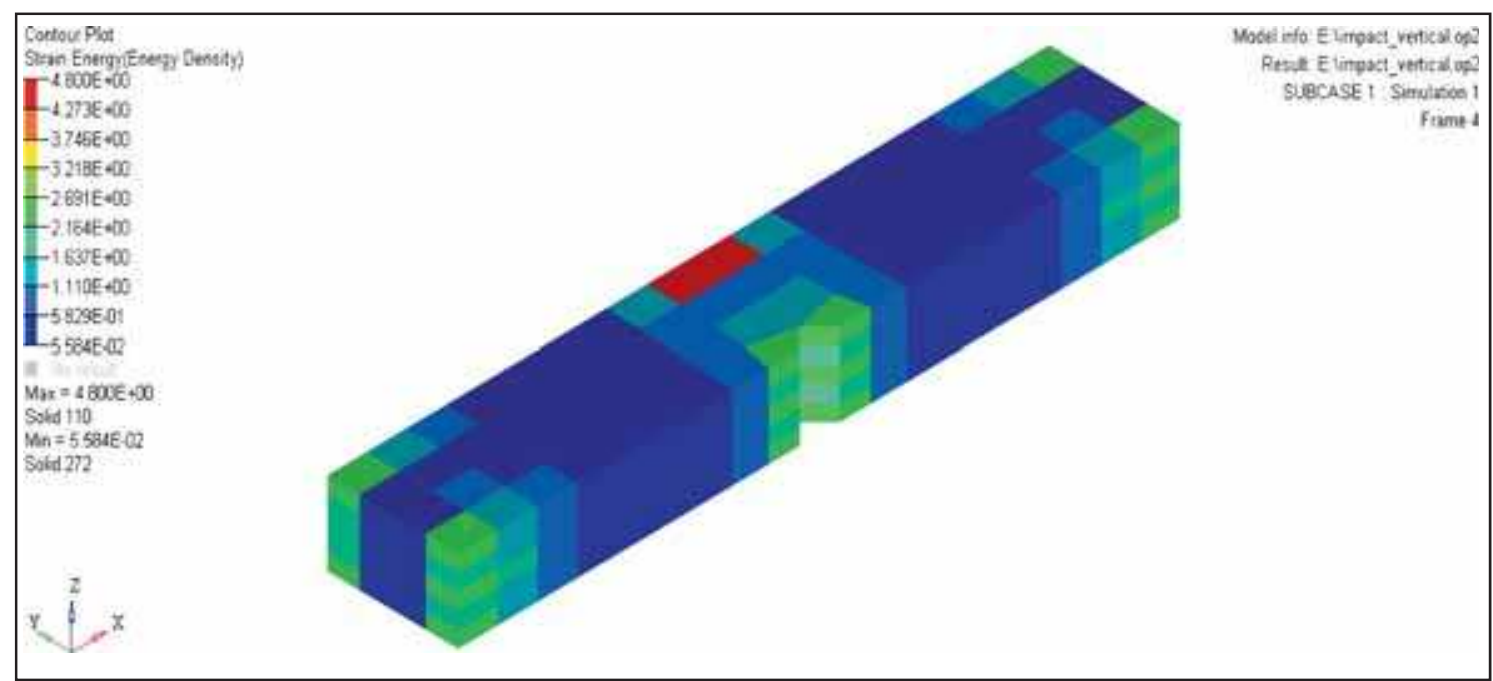

Figure 18. Strain energy distribution of impact test specimen with $90^{\circ}$ fibre orientation. 
kenaf and glass fibres in the fractured surface. Matrix cracking and debonding of fibres from the composites are visible. The images further show that, the interfacial characteristics, internal surface of the fractured specimens due to the application of the tensile load. Thus, the images show the general arrangement of molecules of kenaf-glass fibres and the distribution of fibres are also faintly visible.

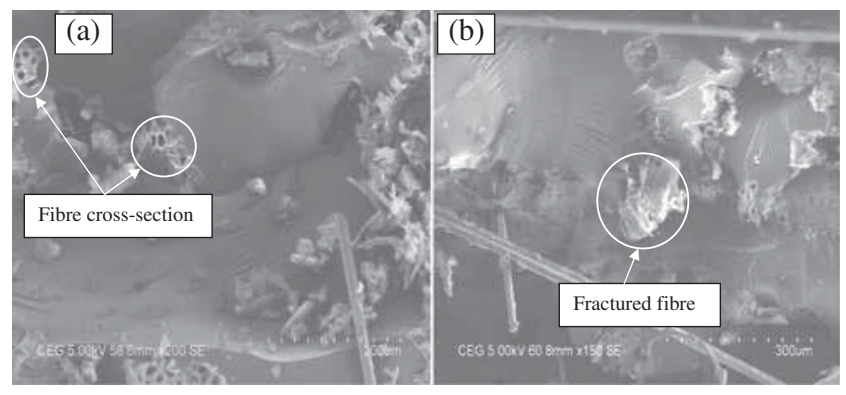

Figure 19. SEM micrographs for kenaf-glass fibre samples subjected to tensile loading: (a) $0^{\circ}$ fibre orientation and (b) $90^{\circ}$ fibre orientation.

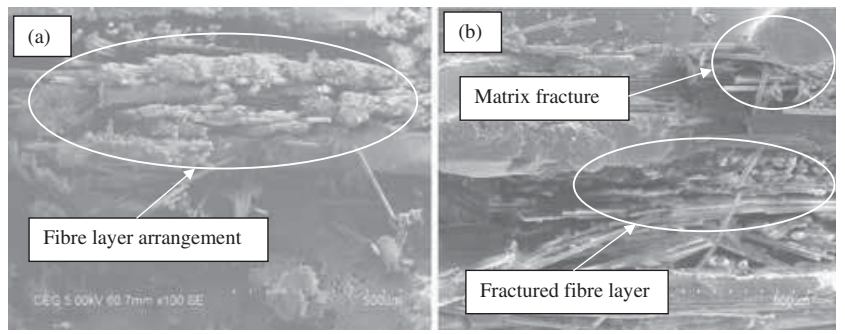

Figure 20. SEM micrographs for kenaf-glass fibre samples subjected to flexural loading: (a) $0^{\circ}$ fibre orientation and (b) $90^{\circ}$ fibre orientation.
The SEM micrographs of the fractured surfaces of the kenaf-glass fibre reinforced composites subjected to flexural loading are presented in figure 20. From the images, it is observed that the layering sequence of the fibres and matrix are very clearly. The images further show that the orientation of fibre, interfacial characteristics, internal surface of the fractured specimens due to the application of the flexural load. Matrix cracking and debonding of fibres from the composites are also visible.

The SEM micrographs of the fractured surfaces of the kenaf-glass fibres reinforced composite samples subjected to impact loading are presented in figure 21 . The figure clearly shows the void formation inside the material due to insufficient flow of resin and fractured fibre particles due to impact load. The images also show the orientation of fibres in the fractured specimen, matrix cracking and debonding of fibres from the matrix. The interfacial characteristics, internal surface of the fractured specimens due to the application of the impact load are also visible.

\section{Conclusion}

In this experimental study, the kenaf and glass fibres reinforced polymer composites have been fabricated with two different fibre orientations of $0^{\circ}$ and $90^{\circ}$. The mechanical properties of these hybrid composites such as tensile strength, impact strength and flexural strength have been evaluated. From the experiment, it has been observed that, the composites with the $0^{\circ}$ fibre orientation withstand the maximum tensile strength of $49.27 \mathrm{MPa}$, flexural strength of 164.35 MPa and impact strength of $6 \mathrm{~J}$. The composite samples with the $90^{\circ}$ fibre orientation can hold the maximum tensile strength of $69.86 \mathrm{MPa}$, flexural strength of $162.566 \mathrm{MPa}$
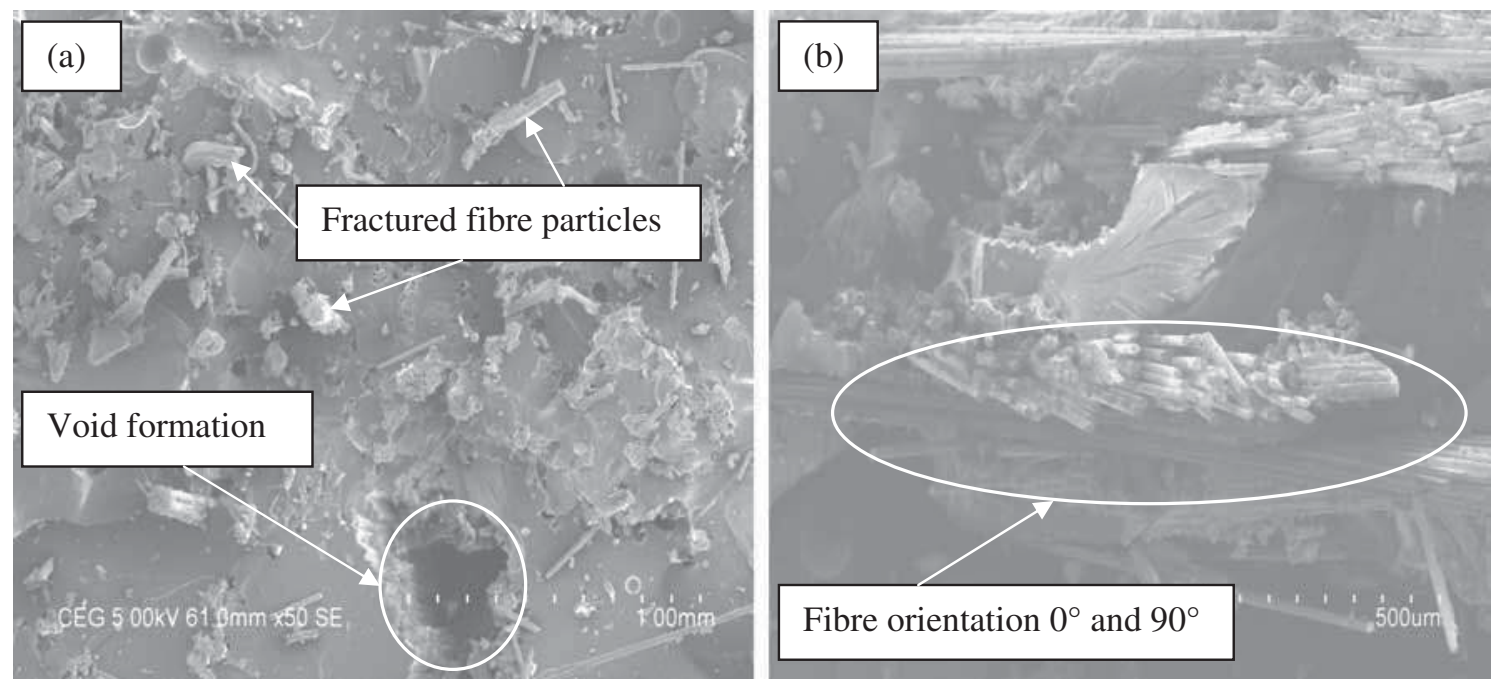

Figure 21. SEM micrographs for kenaf-glass fibre samples subjected to impact loading: (a) $0^{\circ}$ fibre orientation and (b) $90^{\circ}$ fibre orientation. 
and impact strength of $6.66 \mathrm{~J}$. The FEA analysis has been carried out to validate the result by using the simulation software NX Nastran 9. The SEM analysis is carried out to observe the interfacial characteristics and internal surface of the fractured specimen.

From the experimental study, it has been concluded that, kenaf-glass fibre reinforced hybrid composites with $90^{\circ}$ fibre orientation hold more tensile and impact strengths than the composites with $0^{\circ}$ fibre orientation. At the same time, the composites with $0^{\circ}$ orientation have more flexural strength than the composites with $90^{\circ}$ fibre orientation. It has found out that, the discussed FEA model results are very close to the experimental values and hence it is used for predicting properties required for different applications. It is suggested that, this kenaf-glass fibre reinforced hybrid composites is used for useful engineering purposes such as manufacturing of house hold items, sports goods manufacturing and in some structural applications.

\section{References}

[1] Kozlowski R, Mieleniak B, Helwig M and Przepiera A 1999 Polym. Degrad. Stabil. 64523

[2] Akil H M, Omar M F, Mazuki A A M, Safiee S, Ishak Z A M and Bakar A A 2011 Mater. Des. 324107

[3] Liu W, Drzal L T, Mohanthy A K and Misra M 2007 Composites: Part B 38352

[4] Zampaloni M, Pourboghrat F, Yankovich S A, Rodgers B N, Moore J, Drzal L T, Mohanty A K and Misra M 2007 Composites: Part A 381569

[5] Paridah M T, Ahmed A B, SaifulAzry S O A and Ahmed Z 2011 BioResources 65260

[6] Ramesh M, Sudharsan P and Palanikumar K 2015 Appl. Mech. Mater. 766-767 144

[7] Bhoopathi R, Deepa C, Sasikala G and Ramesh M 2015 Appl. Mech. Mater. 766-767 167

[8] Ramesh M, Palanikumar K and Reddy K H 2013 Composites: Part B $\mathbf{4 8} 1$

[9] Ramesh M, Palanikumar K and Reddy K H 2013 Procedia Eng. 51745

[10] Pang C, Shanks R A and Daver F 2015 Composites: Part A 70 52

[11] Aziz S H, Ansell M P, Clarke S J and Panteny S R 2005 Compos. Sci. Technol. 65525

[12] Saba N, Jawaid M, Hakeem K R, Paridah M T, Khalina A and Alothman O Y 2015 Renew. Sustain. Energy Rev. 42 446

[13] Ramesh M, Nijanthan S and Palanikumar K 2015 Appl. Mech. Mater. 766-767 187
[14] Nishino T, Hirao K, Koter M, Nakamae K and Inagaki H 2003 Compos. Sci. Technol. 631281

[15] Saba N, Paridah M T and Jawaid M 2015 Construct. Build. Mater. 7687

[16] Nishino T, Hirao K and Koter M 2006 Composites: Part A 37 2269

[17] Yousif B F, Shalwan A, Chin C W and Ming K C 2012 Mater. Des. 40378

[18] Yang B, Nar M, Visi D K, Allen M, Ayre B, Webber III C L, Lu H and D'Souza N A 2014 Composites: Part B 56926

[19] Davoodi M M, Sapuan S M, Ahmad D, Ali A, Khalina A and Jonoobi M 2010 Mater. Des. 314927

[20] Ismail H, Abdullah A H and Bakar A A 2010 Polym.-Plast. Technol. Eng. 491095

[21] Lai W L, Mariatti M and Jani S M 2008 Polym.-Plast. Technol. Eng. 471193

[22] Yamamoto Y, Zahora D and Netravali A N 2007 Compos. Interfaces 14699

[23] Mokhtar I, Yahya M Y, Kadir M R A and Kambali M F 2013 Polym.-Plast. Technol. Eng. 521140

[24] Farahani G N, Ahmad I and Mosadeghzad Z 2012 Polym.Plast. Technol. Eng. 51634

[25] Abdullah A H, Khalina A and Ali A 2011 Polym.-Plast. Technol. Eng. $\mathbf{5 0} 1362$

[26] Aji I S, Zainudin E S, Sapuan S M, Khalina A and Khairul M D 2012 Polym.-Plast. Technol. Eng. 51146

[27] Taib R M, Hassan H M and Ishak Z A M 2014 Polym.-Plast. Technol. Eng. 53199

[28] Mansor M R, Sapuan S M, Zainudin E S, Nuraini A A and Hambali A 2013 J. Polym. Mater. 30321

[29] Atiqah A, Maleque M A, Jawaid M and Iqbal M 2014 Composites: Part B 5668

[30] Ghani M A A, Salleh Z, Hyie K M, Berhan M N, Taib Y M D and Bakri M A I 2012 Procedia Eng. 411654

[31] Yahaya R, Sapuan S M, Jawaid M, Leman Z and Zainudin E S 2015 Mater. Des. 67173

[32] Ahmed K S and Vijayarangan S. 2008 J. Mater. Process. Technol. 207330

[33] Alavudeen A, Rajini N, Karthikeyan S, Thiruchitrambalam $\mathrm{M}$ and Venkateshwaren N 2015 Mater. Des. 66 246

[34] ASTM standard D638 2002 Standard test method for testing tensile properties of plastics Annual book of ASTM standards

[35] ASTM standard D790 2002 Standard test method for testing flexural properties of unreinforced and reinforced plastics and electrical insulating materials Annual book of ASTM standards

[36] ASTM standard D6110 2002 Standard test method for determining the charpy impact resistance of notched specimens of plastics Annual book of ASTM standards 